\title{
Hypoglycemic and hypolipidaemic effects of some common plants extract in Type 2 diabetic patients at Eldabba area (North Sudan).
}

\author{
Kamal Eldin Gaber, Prof. Usha Singhal, Ogail Daowd \\ Physiology and biochemistry department, Medical College, NIMS university, India
}

\begin{abstract}
Herbal medicines are used in North Sudan to treat diabetes due to their traditional acceptability and availability. The plants are used in crude form or as extract, individually or as a mixture. The objective of this study was to investigate the effects of aqueous extracts of Aloe sinkatana, Guiera senegalensis,Trigonella foenum-graecum, Lupinus albus, Zygophyllum coccineum, Allium cepa, Allium Sativum, Hyphaene thebaica, Balanites aegyptiaca and Acacia albida on blood glucose and lipid profile in Type 2 diabetic patients. Hundred and ten (110) Type 2 diabetics were selected randomly from patients attending to Eldaba Chinese hospital routinely. Ten patients formed the control group and the other hundred patients formed the experimental groups, each group comprising ten patients. Aqueous extract of a particular plant was given to a particular experimental group for thirty days maintaining homogeneity in other variables to allow statistical analysis. Blood samples were collected at the end of the experiment and biochemical parameters were analyzed. Fasting blood sugar level was lowered significantly by the plant extracts. The order of effectiveness was Lupinus albus $120 \pm 9 \mathrm{mg} / \mathrm{dl}, \mathrm{p}<0.02)$, B. aegyptiaca $(121 \pm 18 \mathrm{mg} / \mathrm{dl}, p<0.02)$ Allium Sativum129 $\pm 10 \mathrm{mg} / \mathrm{dl}, \quad p<0.03)$,Allium

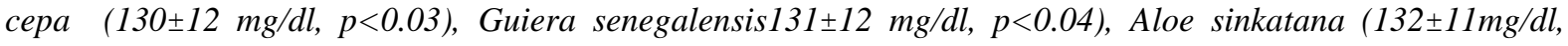
$p<0.05), \quad H$. thebaica $132 \pm 14 \mathrm{mg} / \mathrm{dl}, p<0.05)$ and Trigonella foenum-graecum $(133 \pm 14 \mathrm{mg} / \mathrm{dl}, p<0.05)$. Although some changes were noted in blood sugar level in groups treated with Z. coccineum and Acacia albida extracts but these differences did not reach statistical significance. Lupinus albus, Allium Sativum,Allium cepa Guiera senegalensis1,Aloe sinkatana showed significant $(p<0.04)$ reduction in triglycerides $(T G), T C$, and very low density lipoproteins (VLDL) coupled with significance increase in HDL ( $p=0.03)$. Lupinus albus, Allium Sativum,Allium cepa Guiera senegalensisl and A. sinkatana exhibited anti-diabetic as well as hypolipidemic effects in Type 2 diabetic patients.

Key words: Plant extracts; Biochemical parameters; Anti-diabetic, Hypolipidemic
\end{abstract}

\section{Introduction}

Diabetes is most known metabolic disorder characterized by high level of blood glucose resulting from defects concerning insulin secretion, insulin action, or both. Diabetes is divided into two types, Type I diabetes, which occurs when the body produce failed to produce enough insulin, the primary hormone in the body responsible for regulating the level of sugar within our blood stream. This condition can usually be treated effectively with insulin injections. Type I diabetes is a relatively rare immunological disorder. Till now there is no definite preventive measure against type 1 diabetes. All people even the healthy are susceptible to the disease .They always show normal sensitivity and response to insulin especially in the early stages. Type 1 diabetes traditionally termed "juvenile diabetes" because a majority of these diabetes cases were in children.

On other side $95 \%$ of diabetes cases are Type II diabetes which results mostly due to a combination of insulin resistance and an inadequate compensatory insulin secretory response. Recent scientific papers showed that type $2 \mathrm{DM}$ is common among the adult population of northern Sudan. The crude prevalence was $3.4 \%$ (men, $3.5 \%$; women, $3.4 \%$ ) for diabetes and $2.9 \%$ (men, $2.2 \%$; women, $3.3 \%$ ) for impaired glucose tolerance (IGT) [1].5.5\% of this portion concentrated in the Northern State and $8.6 \%$ in Khartoum State and lowest portion in the western region, $0.9 \%$ [2]. The prevalence was higher in a certain communities such as the tribes of Northern State, particularly in Danagla area where it reached $10.4 \%$.

Among the younger age $7-14$ years the prevalence of the disease was not more than $1 \%$ in school children sample [3].The prevalence of the disease in the Sudanese population is attributed strongly to the high percentage of obesity, approximately in three quarter of the type 2 diabetic patients $40 \%$ of them were obese and they have a family history of diabetes [4]. Type 2 diabetes may be complicated by hypertension, poor metabolic control, smoking, obesity and hyperlipidemia. According to the latest WHO data published in April 2011 Diabetes Mellitus Deaths in Sudan reached 8,000 or 2.17\% of total deaths. Modern medicines like biguanides, sulphonylureas and thiazolidinediones are the ordinary dugs for the treatment of Type 2 diabetes. The undesirable side effect of these drugs pulled the medicinal researchers to obtain new treating materials characterized by high rate of effectiveness, little adverse effects, easily used and less expensive For all these 
things plants have become representing the main target for alternative medicine and plant origin drugs become the drugs of choice.

In the present study, depending on their wide vailability and uses in noth sudan, medicinal plants such as Aloe sinkatana, Guiera senegalensis,Trigonella foenum-graecum ,Lupinus albus, Zygophyllum coccineum, Allium cepa, Allium Sativum, Hyphaene thebaica, Balanites aegyptiaca and Acacia albida were selected to investigate their anti diabetic and hypolipidemic potentials in Type 2 diabetic patients.

\section{Materials and Methods}

The study was conducted at Chinese Hospital in Aldaba city - Sudan. The following criteria were used to include or exclude the patients in the study.

\subsection{Selection Criteria}

*Type 2 diabetic patients with fasting plasma glucose (FPG) level equal to or greater than $140 \mathrm{mg} / \mathrm{dl}$ of blood (WHO Study Group on diabetes mellitus, 1985, Geneva

*Mild Type 2 diabetic patients (FPG) < $180 \mathrm{mg} / \mathrm{dl}$ ) without oral hypoglycemic, anti- hypertensive and hypolipidemic drugs and drugs acting on the hepato-billiary and renal systems.

*Onset of diabetes within $2-3$ years and with no family history of diabetes mellitus/gestational diabetes.

*The patients and control subjects were of either sex (male or female) between 45 - 60 years.

\subsection{Exclusion Criteria}

*Patients with GIT, hepatic, cardiovascular, renal or endocrine disorders which can interfere with the absorption, metabolism and excretion of the study plant

*Patients with any complication of diabetes mellitus

*Pregnant patients

*Smokers.

\subsection{Ethical Process}

After the study was being permitted by the Health ministry office in Eldaba city, written consents from volunteers were obtained. Local language was used to explain the study protocol to the volunteers and a brief description of the study written and presented to the volunteers. All the government of Sudan ethical guidelines to conduct bio-medical researches involving human volunteers were followed.

\subsection{Selection of subjects}

A group of 350 type 2 diabetic patients were selected from the patients attending The Chinese hospital in Eldabba city. 240 people were not taken into account for different reasons. Some patients refused to give written consents; some could not be monitored continuously due to lack of compliance such as frequent changes in life style and dietary intake patterns while other volunteers demanded money for the participation and were eliminated. By applying a random selection basis on the remaining 110 volunteers, eleven groups (ten experimental and one control, ten patients for each) were constructed. All the volunteers were reminded to keep and maintain the homogeneity. Affirmative steps were taken to minimize the effects of other variables prior to the application of the control or treatment modes.

\subsection{Selection of Local agents (LAs)}

Eleven assistants were selected from the local people. The selection was based on focusing on different factors, such as socioeconomic status, acceptability to the volunteers, willingness to participate in the study, intelligence, ability to communicate with the volunteers regarding study objectives and methodology, scientific knowledge, ability to monitor dietary patterns correctly, able to collect and label blood samples etc. One assistant was selected for every 10 volunteers and the local assistants kept in regular contact with the volunteers and the research team. Intensive effort was done to maintain homogeneity of the volunteer's life style and diet.

\subsection{Plants}

Aloe sinkatana, Guiera senegalensis,Trigonella foenum-graecum ,Lupinus albus, Zygophyllum coccineum, Allium cepa, Allium Sativum, Hyphaene thebaica, Balanites aegyptiaca and Acacia albida were collected under hygienic condition from the market of Sudan northern state cities. All selected plants were botanically identified and authenticated by Agricultural guidance, Eldaba Office - Northern State - Sudan. The selected plants were dried in indoor hygienic conditions at $28-30^{\circ} \mathrm{C}$ for about 30 days. After complete drying, the dried materials of each plant were grounded to fine powders using a domestic electric grinder. The powdered plants were stored in sealed dark bottle at normal laboratory conditions to carry out further experimental part. 


\subsection{Preparation of Aqueous Extracts}

$500 \mathrm{~g}$ the plant powder was macerated with one liter of Saphia water in a sterilized glass container with intermittently stirring. The container was left overnight in hygienic dark place. The fluid was filtered through Whatmann filter paper and the filtrate was separated. The filtrate fluid was kept in an air-tight container at $5^{\circ} \mathrm{C}$ till used. Same procedure was followed for all selected plants to prepare their respective aqueous extracts.

\subsection{Study description}

The plant extracts as per documentation in the Sudanese traditional and folklore medicine were given to volunteers selected for the study. The experimental group volunteers received the extracts for consumption in the dose as being consumed by local people, $5 \mathrm{ml} /$ day. Volunteers in control group received only water from the research team for thirty days. The changes in the Blood Biochemistry Parameters (BBP) including, fasting blood glucose (FBS), triglycerides (TG), total cholesterol (TC), high-density-lipoprotein (HDL), low-densitylipoprotein (LDL) and very low-density-lipoprotein (VLDL) in 12 hours fasting conditions were observed before and at the end of the study. Blood samples were collected before the initiation of the study to observe the baseline biochemical profiles of the volunteers and then at after thirty days by professionals assistants. Blood samples were duly labeled and immediately send to the biochemistry lab at Eldaba chinese Hospital.

\subsection{Collection of blood samples}

The selected volunteers (patients and controls) were medically examined and asked to present themselves on a specified date for blood sample collection. They were requested to come with fasting (no food before 12 hours). Blood samples $(4-5 \mathrm{ml}$ ) were drawn from each patient and control subject by vene- puncture through plastic disposable syringes. The blood samples were collected in blood collecting tubes containing proper anticoagulant. The plasma was separated after centrifugation. 12 hours fasting values were taken initially and the end of the experiment.

Triglyceride (TG) and cholesterol were measured by GPO-PAP and CHOD-PAP methods respectively (Parsazmun kit, Karaj, Iran). The direct method was used for determining the HDL, VLDL and LDL by Human kits (Human Gesellschaft fur Biochemica und Diagnostica GmbH, Max-Planck-Ring - D-65205 Wiesbaden Germany) and fasting blood glucose was measured by glucose-oxidize, GOD-PAP method (Parsazmun kit, Karaj, Iran). The other blood bio-chemical parameters were also evaluated before and after the experiment as per standard protocol of Boehringer (Boehringer Mannheim; Instruction sheets for manual assays GmbH Diagnostica).

\subsection{Statistical analysis}

All values were expressed as Mean \pm Standard Deviation (S.D). The results of the study were evaluated by using two-way repeated measures ANOVA. These statistical analyses were conducted by using SPSS statistical software (version 11.5, SPSS Inc. Chicago, IL).

\section{Results}

Prior to the study, clinical Anthropometric and biochemical evaluations were performed in all volunteers. There were a total of 60 men and 50 women involved in the study. All values expressed as mean \pm slandered deviation (SD). Changes in TC, TG, HDL, LDL, VLDL and FBS were summarized in Table (1). There were significant changes observed in biochemical parameters in experimental groups (plants treated groups). Fasting blood sugar level was lowered significantly by the plant extracts. The order of effectiveness was Lupinus albus $120 \pm 9 \mathrm{mg} / \mathrm{dl}, \mathrm{p}<0.02)$, B. aegyptiaca $(121 \pm 18 \mathrm{mg} / \mathrm{dl}, \mathrm{p}<0.02)$ Allium Sativum129 $\pm 10 \mathrm{mg} / \mathrm{dl}$, $\mathrm{p}<0.03)$,Allium cepa $(130 \pm 12 \mathrm{mg} / \mathrm{dl}, \mathrm{p}<0.03)$, Guiera senegalensis $131 \pm 12 \mathrm{mg} / \mathrm{dl}, \mathrm{p}<0.04)$, A sinkatana $(132 \pm 11 \mathrm{mg} / \mathrm{dl}, \mathrm{p}<0.05)$, H. thebaica $132 \pm 14 \mathrm{mg} / \mathrm{dl}, \mathrm{p}<0.05)$ and Trigonella foenum-graecum $(133 \pm 14 \mathrm{mg} / \mathrm{dl}$, $\mathrm{p}<0.05)$.

Lupinus albus,Allium Sativum,Allium cepa Guiera senegalensis, Aloe sinkatana showed significant $(\mathrm{p}<0.04)$ reduction in triglycerides $(\mathrm{TG}), \mathrm{TC}$, and very low density lipoproteins (VLDL) coupled with significance increase in HDL ( $\mathrm{p}=0.03$ ). Lupinus albus, Allium Sativum,Allium cepa Guiera senegalensis 1 and Aloe sinkatana exhibited anti-diabetic as well as hypolipidemic effects in Type 2 diabetic patients.

Although some changes were noted in the body weight, blood urea, serum creatinine, serum bilirubin sreum glutamic pyruvic transaminase (SGPT) and serum glutamic oxaloacetic transaminase (SGOT) as shown in table (2) but these differences did not reach statistical significance.

Age-specific data analysis in both the experimental and control groups showed no significant variations with age and therefore data in both groups were analyzed as a whole. In addition, there were no significant effects of gender observed. 
Table (1)

\begin{tabular}{|l|l|l|l|l|l|l|}
\hline Group & $\begin{array}{l}\text { TC } \\
(\mathrm{mg} / \mathrm{dl})\end{array}$ & HDL $(\mathrm{mg} / \mathrm{dl})$ & LDL $(\mathrm{mg} / \mathrm{dl})$ & VLDL(mg/dl) & TG(mg/dl) & FBS (mg/dl) \\
\hline Control & $152 \pm 14$ & $33 \pm 5$ & $92 \pm 17$ & $27 \pm 9$ & $135 \pm 1$ & $152 \pm 11$ \\
\hline Acacia albida & $151 \pm 15$ & $33 \pm 7$ & $89 \pm 19$ & $27 \pm 8$ & $132 \pm 17$ & $149 \pm 11$ \\
\hline G.senegalensis & $144 \pm 18$ & $32 \pm 8$ & $92 \pm 09$ & $20 \pm 8$ & $99 \pm 12$ & $131 \pm 12$ \\
\hline $\begin{array}{l}\text { T.foenum- } \\
\text { graecum }\end{array}$ & $145 \pm 19$ & $27 \pm 6$ & $102 \pm 12$ & $15 \pm 9^{*}$ & $77 \pm 15^{*}$ & $133 \pm 14$ \\
\hline Lupinus albus & $130 \pm 15$ & $22 \pm 4$ & $91 \pm 16$ & $18 \pm 5$ & $95 \pm 15$ & $120 \pm 9^{*}$ \\
\hline Z. coccineum, & $149 \pm 15$ & $32 \pm 4$ & $102 \pm 8$ & $25 \pm 9$ & $133 \pm 11$ & $148 \pm 14$ \\
\hline Allium cepa & $124 \pm 19^{*}$ & $22 \pm 6$ & $83 \pm 15$ & $19 \pm 7$ & $95 \pm 12$ & $130 \pm 12^{*}$ \\
\hline Allium Sativum & $133 \pm 15$ & $27 \pm 8$ & $86 \pm 13$ & $17 \pm 9^{*}$ & $100 \pm 9$ & $129 \pm 10^{*}$ \\
\hline H. thebaica & $137 \pm 15^{*}$ & $27 \pm 4^{*}$ & $85 \pm 19^{*}$ & $25 \pm 8$ & $127 \pm 15$ & $132 \pm 14$ \\
\hline B. aegyptiaca & $121 \pm 18 *$ & $22 \pm 4$ & $85 \pm 13$ & $19 \pm 8$ & $97 \pm 15^{*}$ & $138 \pm 10$ \\
\hline A. sinkatana & $130 \pm 11$ & $24 \pm 5$ & $83 \pm 13$ & $23 \pm 8$ & $122 \pm 15$ & $132 \pm 14$ \\
\hline
\end{tabular}

Table (2)

\begin{tabular}{|l|l|l|l|l|l|l|}
\hline Parameters & $\begin{array}{l}\text { Weight } \\
\text { (kg) }\end{array}$ & $\begin{array}{l}\text { S.Creatinine } \\
(\mathbf{m g} / \mathbf{d l})\end{array}$ & $\begin{array}{l}\text { Blood Urea } \\
(\mathbf{m g} / \mathbf{d l})\end{array}$ & $\begin{array}{l}\text { S. Bilrubin } \\
(\mathbf{m g} / \mathbf{d l})\end{array}$ & $\begin{array}{l}\text { SGPT } \\
(\mathbf{I U} / \mathbf{L})\end{array}$ & $\begin{array}{l}\text { SGOT } \\
\text { (IU/L) }\end{array}$ \\
\hline Control & $73.7 \pm 2.6$ & $2.0 \pm 0.7$ & $28 \pm 5.2$ & $0.7 \pm 0.5$ & $33 \pm 4.2$ & $33 \pm 2.5$ \\
\hline $\begin{array}{l}\text { A. sinkatana } \\
\text { G1.7 } \pm 4.6\end{array}$ & $2.1 \pm 0.4$ & $26 \pm 6.1$ & $0.6 \pm 0.8$ & $35 \pm 3.2$ & $35 \pm 2.0$ \\
\hline G.senegalensis & $76.9 \pm 2.9$ & $1.8 \pm 0.8$ & $29 \pm 8.3$ & $0.8 \pm 0.8$ & $32 \pm 3.8$ & $30 \pm 4.5$ \\
\hline $\begin{array}{l}\text { T.foenum- } \\
\text { graecum }\end{array}$ & $72.6 \pm 3.7$ & $1.7 \pm 0.9$ & $26 \pm 6.7$ & $0.7 \pm 1.2$ & $35 \pm 2.2$ & $35 \pm 3.5$ \\
\hline Lupinus albus & $73.7 \pm 2.5$ & $2.3 \pm 0.5$ & $29 \pm 4.2$ & $0.8 \pm 0.6$ & $32 \pm 2.2$ & $35 \pm 5.5$ \\
\hline Z. coccineum, & $71.6 \pm 2.6$ & $2.0 \pm 0.7$ & $24 \pm 5.8$ & $1.0 \pm 0.7$ & $34 \pm 1.8$ & $31 \pm 4.8$ \\
\hline Allium cepa & $70.3 \pm 3.3$ & $2.6 \pm 1.1$ & $23 \pm 3.7$ & $0.9 \pm 0.5$ & $35 \pm 2.8$ & $32 \pm 5.5$ \\
\hline Allium Sativum & $72.7 \pm 3.6$ & $2.4 \pm 0.7$ & $27 \pm 9.2$ & $0.6 \pm 1.5$ & $33 \pm 3.8$ \\
\hline H. thebaica & $70.7 \pm 3.8$ & $1.9 \pm 0.9$ & $25 \pm 7.3$ & $0.8 \pm 0.2$ & $31 \pm 3.2$ & $34 \pm 6.2$ \\
\hline B. aegyptiaca & $69.7 \pm 2.8$ & $2.2 \pm 1.3$ & $27 \pm 6.6$ & $0.7 \pm 1.3$ & $36 \pm 2.26$ \\
\hline Acacia albida & $74.7 \pm 2.3$ & $2.0 \pm 1.5$ & $29 \pm 5.4$ & $0.6 \pm 1.6$ & $34 \pm 3.1$ & $35 \pm 4.0$ \\
\hline
\end{tabular}

\section{Discussion}

Although different types of oral hypoglycaemic agents are available along with insulin for the treatment of diabetes mellitus, patients' demand for the use of natural products with antidiabetic activity is on the increase. Insulin cannot be used orally and the continuous use of synthetic drugs has its risk of side effects and toxicity [5] [6] Therefore, the need for the use of effective herbal drugs with less side effects and relatively cheap is imperative [7] [8]. A number of plants were found to possess hypoglycemic effects and the possible mechanism suggested for such hypoglycemic actions could occurs at the pancrease level by protectiving, regenerating, repairing pancreatic beta cells, increasing the size and number of cells in the islets of Langerhans [ 9], stimulation of insulin secretion from surviving beta cells of islets or/and inhibition of insulin degradative processes [ 10],providing certain necessary elements like calcium, zinc, magnesium, manganese and copper for the beta-cells. [9], While other possible mechanism could be exerted by inhibition in renal glucose reabsorption, [11] stimulate reduction in insulin resistance, [12] stimulation of glycogenesis and hepatic glycolysis, [13] 
improveming the digestion along with reducing blood sugar and urea [14] or may act through the inhibition of glucocidase, cortisol and alpha-amylase [15]

Previous studies concerning the phytochemical constituents of the medicinal plants, revealed the presence of secondary metabolites that were shown to have hypoglycemic and hypolipidemic effects such as Saponins [16] alkaloids [17] flavonoids [18] [19], tannin [20], phenol derivatives [21] and Terpenoids. [22] Hence, the plant constituents could have different sites of action within the body. That is to say such hypoglycemic effects of plant extracts could also be due to their insulin like actions [23].

In diabetes, hyperglycemia is accompanied with dyslipidemia [24] characterized by increase in TG, TC, LDL, VLDL, and TG and fall in HDL. This altered serum lipid profile was reversed towards normal after treatment with the plant extracts. The possible mechanism through which the plants exert their antihyperlipidemic effect might include the changed activity of cholesterol biosynthesis enzymes, changed level of lipolysis which is under the control of insulin or direct hypolipidemic effect mediated through other mechanisms [25].

There are several studies regarding the use of herbal extract for the treatment of diabetes. The available literatures suggest that herbal extracts are well tolerated with negligible side effects during treatment of diabetes. Aloe sinkatana is a sudanese aloe species cultivated in Sinkate area in eastern of Sudan. Their leaves are used to treat diabetic and inflammatory colon[26] The oral a dminstration of ethanolic extract of G. senegalensis to glucose-loaded rats showed a hyperglycemic effect in these animals, which was significant [27] Trigonella foenum-graecum extract can lower blood glucose, blood lipid levels and improve hemorheological properties following repeated treatment for 6 weeks[28]. Egyption study concerning Lupinus albus and Zygophyllum coccineum, known locally as termis and Kammun respectively demonstrated that the treatment of diabetic rats with these herbs have exerted a considerable hypoglycemic effect. In addition, these herbs could ameliorate the impaired renal function and inhibit liver damage associated with alloxan diabetes [29]. Garlic extract supplementation improves blood lipid profile, strengthens blood antioxidant potential, and causes significant reductions in systolic and diastolic blood pressures. It also leads to a decrease in the level of oxidation product (MDA) in the blood samples, which demonstrates reduced oxidation reactions in the body [30]. Onion (Allium cepa) and garlic (Allium Sativum) exhibited anti-diabetic, antibiotic and hypocholestrolaemic actions and they had been used in the traditional medical practice of many cultures to treat cardiovascular and other disorders. [31] [32].

Supplementation of the water soluble fraction of Hyphaene thebaica (HT) epicarp.(WF) improved glucose and insulin tolerance and significantly lowered blood glycosylated hemoglobin levels [33].

Balanites aegyptiaca fruits being used by Egyptians Ancient in traditional medicine and aqueous extract of Balanites aegyptiaca fruits had hypoglycemic effect instreptozotocin induced diabetic rats [34].

Recent studies on laboratory rats provided evidence that Acacia albida root bark possessed hypoglycaemic activity, which may justify its traditional use in diabetes mellitus [35].

\section{Conclusion}

In conclusion, Sudan is one of third world countries with a large portion of people suffering from DM and its complications. A large portion of the population lives in rural sectors with poor health infrastructures. The high costs for therapeutic treatment has compelled physicians and researchers to look for alternative less cost medicine cost to treat Type 2 diabetes and minimize its complications.. Therefore, medicinal plants and their products are best substitute for the treatment of Type 2 diabetes due to their easy availability, low cost, minimum side effects and greater acceptance amongst the users. This study indicated use of aqueous extracts of Aloe sinkatana, Guiera senegalensis,Trigonella foenum-graecum ,Lupinus albus, Zygophyllum coccineum, Allium cepa, Allium Sativum, Hyphaene thebaica, Balanites aegyptiaca and Acacia albida exhibited antidiabetic as well as hypolipidaemic effects Type 2 diabetic patients. However, further biochemical studies should be conducted to promote using of these herbs as antidiabetic agents.

\section{Acknowledgment}

The authors express deep thanks to the volunteers, their families and local people of Eldab area for their involvement in this research work. The authors also extend sincere gratitude to the all member in Eldaba Chinese Hospital for valuable support in this research work.

\section{References}

[1]. Elbagir MN, Eltom MA, Elmahadi EM, Kadam IM, Berne C,A population-based study of the prevalence of diabetes and impaired glucose tolerance in adults in northern Sudan. Diabetes Care.19(10), Oct 19961126-8.

[2]. Moawia. A, Clinical and Biochemical Features of Adult Diabetes Mellitus in Sudan, 2006,6206 ISBN 91-554-6542-0 urn:nbn:se:uu:diva-6816.

[3]. Elamin. A, Omer. MIA, Hofvander. Y, Tuvemo.T, Prevalence of insulindependent diabetes mellitus (IDDM) in school children in Khartoum, Sudan.Diabetes Care,1989,12: 430-2. 
[4]. Elmahadi. EMA, Salih. AR, Mukhtar. E, Patterns of diabetes mellitus in the Sudan, Trop geogr Med.4, 1989, 353-5.

[5]. Holmann. RR, Turner. RC, Textbook of diabetes. Oxford Blackwell,1991.

[6]. Chattopadhyay. RR,. Hypoglycaemic effect of Ocimum sanctum leaf extract in normal and streptozotocin-diabetic rats. Indian J Exp Biol, 31, 1993891-893.

[7]. Choi. JS, Yokozawa. T, Oura H. Improvement of hyperglycaemia by methanolic extracts of Prunus davidana stem and its main component, pruning. Planta med..57:208-211,1991.

[8]. Erenmemisoglu. A, Kelestimur. F, Koker. AH, Ustun. H, Tekol. Y, Ustdal. M, Hypoglycaemic effect of Zizyphus jujube leaves. J Pharm Pharmacol, 47, 1995, 72-74.

[9]. Mohamed. B, Abderrahim. Z, Hassane. M, Abdelhafid. T, Abdelkhaleq. L, Medicinal plants with potential antidiabetic activity - A review of ten years of herbal medicine research (1990-2000). Int J Diabetes Metabol, 14, 2006. 1-25.

[10]. Pulok. KM, Kuntal. M, Kakali. M, Peter. JH, Leads from Indian medicinal plants with hypoglycemic potentials, J Ethnopharmacol,106, 20061-28.

[11]. Eddouks. M, Maghrani. M, Lemhadri. A, Ouahidi. ML, Jouad. H, Ethnopharmacological survey of medicinal plants used for the treatment of diabetes mellitus, hypertension and cardiac diseases in the south-east region of Morocco (Tafilalet), $\mathrm{J}$ Ethnopharmacol,82,2002, 97-103.

[12]. Esmaeili. MA, Yazdanparast. R, Hypoglycaemic effect of Teucrium polium: studies with rat pancreatic islets, J Ethnopharmacol, 95, 2004, 27-30.

[13]. Miura. T, Itoh. C, Iwamoto. N, Aato. M, Kawai. M, Park. SR, Suziki. I, Hypoglycemic activity of the fruit of the Momordica charantia in Type 2 diabetic mice, J Nutr Sci Vitaminol (Tokyo), 47, 2001, 340-4.

[14]. Krishnan. SH, A preliminary communication of the action of Aegle marmelos (Bael) on heart. Ind J Med Res, 56, $1968,327-31$.

[15]. Heidari. R, Zareae. S, Heidarizadeh. M. Extraction, Purification, and Inhibitory Effect of Alpha-Amylase Inhibitor from Wheat(Triticum aestivum Var. Zarrin). Pakistan J Nutr, 4, 2005,101-5.

[16]. Abdel-Zaher.A.O, Salim. S.Y, Assaf, M.H and Abdel-hady. R.H,. Antidiabetic activity of Zizyphus spina-christi leaves; Journal of ethnopharmacology.101, 2005, 129-138.

[17]. Li. W.L, ZhengH. C, Bukru. Jand Dekimpe. N, Natural Medicines used in traditional Chinese medicine system for therapy of diabetes mellitus, Journal of ethnopharmacology, 92, 2004, 1-21.

[18]. Coskul. O, Kanter. M, Korkmaz. A and Oter.S, Quercetin a flavonoid antioxidant prevents and protects streprozocin- induced oxidative stress and $\beta$-cell damage in rat pancreas, Pharmacological research,51,2005,117-123.

[19]. Tanko.Y, Yaro. A.H, Isa. A, Erima.,M, Saleh. M.A and Mohammed.A, Toxicological and hypoglycemic studies on the leaves of Cissampelos Mucronata (Menispermaceae) on blood glucose levels of stre ptozocin -induced diabetic wistar rats, Journal of medicinal plants research1(5), 2007.113-116,

[20]. Klein. G, Kim. J, Himmeldirk. K,Cao.Y, Chen. X, Antidiabetes an d anti-obesity activity of lagerstroemia speciosa. Evidence-Based Complementary and AlternativeMedicine (Ecam), 4(4), 2007.401-407.

[21]. Alexandru V, Balan M, Gasper A, and Coroiu V. Antioxida nt activity of phenolics and flavonoid content of some selected Romanian medicinal plants. Planta med, 73 (9),2007, 797-1034.

[22]. Ms .L and Thoung. PT, Stimulation of glucose uptake by triterpenoids from Weigela subsessilis,. Phytother Res, 24, 2010, 49-53.

[23]. Zohri AN, Abdel-Gawad K, Saber S, Antibacterial, antidermatophytic and antitoxigenic activities of onion (Allium cepa L.) oil, Microbiol Res,150(2), May, $1995,167-72$.

[24]. M. S. De Sereday, C. Gonzalez, D. Giorgini et al., "Prevalence of diabetes, obesity, hypertension and hyperlipidemia in the central area of Argentina," Diabetes and Metabolism, vol. 30, no. 4, 2004, pp. 335-339.

[25]. S. B. Sharma, A. Nasir, K. M. Prabhu, P. S. Murthy, and G. Dev, "Hypoglycaemic and hypolipidemic effect of ethanolic extract of seeds of Eugenia jambolana in alloxan-induced diabetic rabbits," Journal of Ethnopharmacology, vol. 85, no. 2-3, 2003, pp. 201206.

[26]. H. S.Khalid, H. H. Elkamali and A. M. Atta Elmanan, Trade of Sudanese Natural Medicinals and their role in Human and Wildlife Health Care

[27]. Reem. H, The hypoglycemic and anti-diabetic effects of Guiera Senegalensis and Medicago sativa, M.Sc Thesis, University of Khartoum, 2012

[28]. Shani, J., Goldschmied, A., Joseph, B., Ahronson, Z., Sulman, F.G, Hypoglycemic effect of Trigonella foenum graecum and Lupinus termis leguminosae seeds and their major alkaloids in alloxan-diabetic and normal rats. Arch. Inten. Pharmacodyn, 210, 1974, 27-34

[29]. Hamdy A. Mansour, Al-Sayeda A. Newairy , M.I. Yousef, S.A. Sheweita, .Biochemical study on the effects of some Egyptian herbs in alloxan-induced diabetic rats Toxicology $170,2002,221-228$

[30]. Durak I, Kavutcu M, Aytac B, Avci A, Devrim E, Ozbek H, Oztürk HS, Effects of garlic extract consumption on blood lipid and oxidant/antioxidant parameters in humans with high blood cholesterol, J Nutr Biochem, 15(6), June, 2004,373-7.

[31]. Augusti KT. Therapeutic values of onion (Allium cepa L.) and garlic (Allium Sativum L.). Indian J Exp Biol 1996; 34: 634-640.

[32]. Kendler BS. Garlic (Allium Sativum) and onion (Allium cepa): a review of their relationship to cardiovascular disease. Prev Med 1987; 16: 670-85.

[33]. Salib JY, Michael HN, Eskande EF, Anti-diabetic properties of flavonoid compounds isolated from Hyphaene thebaica epicarp on alloxan induced diabetic rats, Pharmacognosy Res. 5(1):22-9. Jan 2013.

[34]. Eskander, E.F, Effect of Balanites aegyptiaca on serum glucose and insulin level in normal and alloxan-diabetic mice, Egypt. J. Appl. Sci. 9 (2), 1994, $15-25$.

[35]. Y. Salisu*, A. Agunu, M.S. Abubakar and G. Ibrahim, HYPOGLYCAEMIC EFFECTS OF ACACIA ALBIDA DEL. (MIMOSACEAE) METHANOL ROOT BARK EXTRACT .Salisu et al., Nig. Journ. Pharm. Sci., March,2009, Vol. 8 No. 1, P. 667272 